\title{
Effects of Surfactants on the Performance of ZrO2 Humidity Sensors
}

\author{
Chunjie Wang ${ }^{1, a}$, Jitao $\mathrm{Jie}^{1, \mathrm{~b}}$ and Yue Wang ${ }^{2, \mathrm{c}^{*}}$ \\ ${ }^{1}$ College of Engineering, Bohai University, Jinzhou, 121013, China \\ ${ }^{2}$ College of New Energy, Bohai University, Jinzhou, 121013, China \\ acjwang@foxmail.com, b22340379@qq.com, cwangsuiyue@foxmail.com
}

\section{Keywords: Sensor; Surfactant; Resistance; ZrO2}

\begin{abstract}
Nano-sized $\mathrm{ZrO} 2$ powders were synthesized by hydrothermal method with two types of surfactants (cetyltrimethyl ammonium bromide (cationic surfactant, CTAB), and sodium dodecylbenzene sulfonate (anionic surfactant, SDBS)). The phase structures and morphologies of the products were investigated by X-ray diffraction and scanning electron microscope. The sample with CTAB as surfactant ( $\mathrm{ZrO} 2-\mathrm{C})$ shows larger specific surface area and smaller particle size than $\mathrm{ZrO} 2-\mathrm{S}$. The humidity sensor fabricated by $\mathrm{ZrO} 2-\mathrm{C}$ shows higher performance than the sample used SDBS as surfactant. The impedance of the $\mathrm{ZrO} 2-\mathrm{C}$ sensor decreases by about four orders of magnitude with relative humidity ( $\mathrm{RH}$ ) changed from 11 to $95 \%$. The response and recovery time are 60 and $70 \mathrm{~s}$, respectively. These results indicate that the performance of $\mathrm{ZrO} 2$ humidity sensors can be improved effectively by the addition of cationic surfactant.
\end{abstract}

\section{Introduction}

In the past few years, humidity sensors as one of the most important chemical sensors have attracted much attention due to their broad applications in environment protection, agriculture, and industrial production driven by the recognized importance of vapor concentration $[1,2]$. Several materials have been studied as sensing elements in humidity sensors. The desirable characteristics of ideal humidity sensing materials should possess: good sensitivity over the entire range of humidity and temperature, stable chemical and physical property over time and thermal cycling, rapid response and recovery time, and low hysteresis [3]. Generally speaking, the humidity sensors are mainly fabricated by two kinds of materials: organic polymer films and porous ceramic films [4]. By comparison, ceramic humidity sensors are widely used than polymeric sensor due to the improved thermal, chemical and physics stability. The main disadvantages for polymeric sensors are the low operation temperature, poor physical and chemical stability, and weak mechanical strength, while that for porous ceramic sensors with porous structured films are the dull response and recovery time.

On the other hand, for humidity sensors, the impedance changes when water molecules were adsorbed onto the surface of the humidity sensor with porous structure. As well known, nano-sized materials show small particle size and large specific surface area. The nano-sized porous structure helps to increase the surface area, and facilitates the adsorption ability of water molecules. Thus, nanomaterials have more surface active sites and stronger adsorption ability than bulk materials.

Recent years, Zirconia ceramics have received special attention due to their potential applications in number of devices, such as ion conductors in solid oxide fuel cells, sensors and catalytic appliances. The studies regarding the structure, performance of pure and doped $\mathrm{ZrO}_{2}$ humidity sensors have been performed. Wang et al reported the performance of $\mathrm{ZrO}_{2}$ nanorods humidity sensor [5]. Su et al devoted their works to the $\mathrm{Y}^{3+}$ and $\mathrm{Mg}^{2+}$ doped zirconia thick film humidity sensors [6]. Cosentino et al studied the zirconia-titania porous ceramics for humidity sensors [7].

Properties of the obtained products largely depend on the synthesis conditions (such as synthesis method, precursor, and surfactant). In order to obtain fine nanocrystlline powders, various method have been proposed. In contrast, the hydrothermal technique is an ideal route for synthesizing varous nano-sized materials with high purity and controlled structure at relatively low reaction 
temperature [8]. Due to the high surface energy of nanoparticels, however, the products are easy to coagulate and difficult to disperse in water. It has been reported that serious agglomeration has an adverse effect on the properties of sensors during the filming process. To the best of our knowledge, nevertheless, the systematic comparison of the influence of different types of surfactants (cationic and anionic) on the physicochemical properties of $\mathrm{ZrO}_{2}$ nano-sized film has not been reported. To improve the performance of sensor, it is essential to make insight into the influence of different types of surfactants on the particles.

In this article, nano-sized $\mathrm{ZrO}_{2}$ were synthesized with two types of surfactants (CTAB (cationic), and SDBS (anionic)) via hydrothermal mothed. The humidity sensing properties, response and recovery time, and hysteresis characteristics of the corresponding sensors were investigated in the relative humidity range from $11 \%$ to $95 \%$ with various frequencies at different temperatures. The main purpose of this study is to explore the most favorable surfactant for sensors materials among these three kinds of surfactants.

\section{Experimental}

In order to obtain $\mathrm{ZrO}_{2}$ nanoparticles, a certain amount of surfactants (2 wt.\%, CTAB or SDBS, Shanghai Chemicals Ltd. ) were added into $50 \mathrm{ml}$ of $\mathrm{ZrOCl}_{2} \cdot 8 \mathrm{H}_{2} \mathrm{O}(99.99 \%$, Chenghai Chemical of Guangdong) solution $(0.1 \mathrm{M})$ under magnetic stirring. The $\mathrm{pH}$ value of the solution was adjusted to 7 by adding sodium hydroxide solution $(\mathrm{NaOH}, 2 \mathrm{M})$. Then, $\mathrm{ZrO}_{2}$ nanopowders were obtained by hydrothermal treatment for the mixed solution in a Teflon autoclave at $180{ }^{\circ} \mathrm{C}$ for $24 \mathrm{~h}$. The precipitates were filtered and washed with distilled water and ethanol for several times, and dried at $60{ }^{\circ} \mathrm{C}$ for $24 \mathrm{~h}$. In this paper, the produced $\mathrm{ZrO}_{2}$ nanopowders were designated as $\mathrm{ZrO}_{2}-\mathrm{C}$ and $\mathrm{ZrO}_{2}-\mathrm{S}$, respectively.

The crystalline phases of $\mathrm{ZrO}_{2}$ nanocrystalline powders were examined by means of powder $\mathrm{X}$-ray diffraction (XRD, Bruker D8 Focus powder X-ray diffractometer) using $\mathrm{Cu} \mathrm{K} \alpha$ radiation $(\lambda=1.5406 \AA)$ with a scanning rate of $5^{\circ} \cdot \mathrm{min}^{-1}$. The lattice parameters were calculated based on the XRD patterns. The average particle size of nanopowders $(D)$ was determined by Scherrer's equation:

$$
D=\lambda \frac{K}{\beta \cos \theta}
$$

Where $\lambda$ is the wavelength of the $\mathrm{X}$-ray radiation, $\theta$ is the diffraction angle, $K$ is a constant $(0.89)$ and $\beta$ is the corrected full-width half maximum (FWHM).

The specific surface area $\left(\mathrm{S}_{\mathrm{BET}}\right)$ was determined by applying Brunauer-Emmet-Teller (BET) equation $[15,16]$ with a Micromeritics ASAP2020 instrument. The powder microstructure and particle size were examined by a field emission scanning electron microscope (SEM, Hitachi S-4800).

In order to fabricate the humidity sensors, the $\mathrm{ZrO}_{2}$ nanopowders were dispersed in ethanol by magnetic stirring $(30 \mathrm{~min})$ and dropped onto a ceramic substrate to form a $\mathrm{ZrO}_{2}$ film with a thickness of $10 \mu \mathrm{m}$. The equipment for the measurement was a ZL-5 model LCR analyzer (Shanghai, China). The impedance of the sensors was measured by putting the sensor into several chambers with different relative humidity $(\mathrm{RH})$ levels. The relative humidity levels were generated by using $\mathrm{MgCl}_{2}, \mathrm{Mg}\left(\mathrm{NO}_{3}\right)_{3}, \mathrm{NaCl}, \mathrm{KCl}$, and $\mathrm{KNO}_{3}$ saturated salt solutions, and the corresponding $\mathrm{RH}$ values were $33,54,75,85$, and $95 \%$, respectively. The humidity of laboratory atmosphere was $15.7 \%$ RH controlled by an automatic drier. Fig. 1 shows the schematic diagram of the sensor structure. 


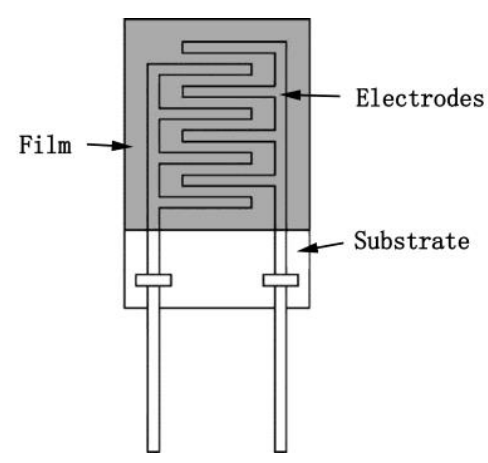

Figure 1. Schematic diagram of the sensor structure.

\section{Results and Discussion}

The phase structures of both samples were investigated by XRD at room temperature, as shown in Fig. 2. It can be noted that the diffraction peaks in the XRD patterns of two samples implying that both samples in a cubic structure. The peaks at about $29.2^{\circ}, 34.2^{\circ}, 50.1^{\circ}$, and $59.6^{\circ}$ can be well indexed to the (111), (200), (220) and (311) planes. Furthermore, the diffraction peak width of $\mathrm{ZrO}_{2}-\mathrm{C}$ is wider than that of $\mathrm{ZrO}_{2}-\mathrm{S}$, indicating that the grain size of $\mathrm{ZrO}_{2}-\mathrm{C}$ is smaller than that of $\mathrm{ZrO}_{2}$-S. Besides, no obvious difference can be observed between both samples. In addition, the crystalline sizes of both samples were also investigated. The crystal size was calculated by Scherrer's equation as mentioned in experimental section. For $\mathrm{ZrO}_{2}-\mathrm{C}$, the average crystalline size is $13.2 \mathrm{~nm}$, while that of $\mathrm{ZrO}_{2}-\mathrm{S}$ is $25.72 \mathrm{~nm}$. In addition, for nano-structured films, the specific surface area is an important parameter to determine the performance of sensor. The value for $\mathrm{ZrO}_{2}-\mathrm{C}$ and $\mathrm{ZrO}_{2}-\mathrm{S}$ are 126.54 and $97.33 \mathrm{~m}^{2} \cdot \mathrm{g}^{-1}$, respectively. As well known that, for nanomaterials, the crystalline size is closed related to the specific surface area. The smaller the crystalline size is, the higher the specific surface area will be.

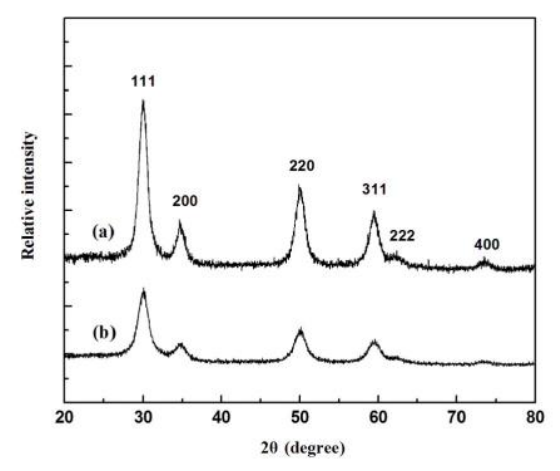

Figure 2. XRD patterns of as-prepared products: (a) $\mathrm{ZrO}_{2}-\mathrm{S}$; (b) $\mathrm{ZrO}_{2}-\mathrm{C}$.

The morphology and particle size of the synthesized materials were further characterized by SEM. Fig. 3 is the typical SEM images of $\mathrm{ZrO}_{2}-\mathrm{C}$ and $\mathrm{ZrO}_{2}-\mathrm{S}$. Clearly, both samples are composed of spherical particles, and the average particles size of $\mathrm{ZrO}_{2}-\mathrm{C}(14.32 \mathrm{~nm})$ is smaller than that of $\mathrm{ZrO}_{2}-\mathrm{S}(25.76 \mathrm{~nm})$. The determined mean particle size is the average value of 20 particles selected randomly. The average particle size obtained from SEM pattern is consistent with that calculated from Scherrer's equation. 

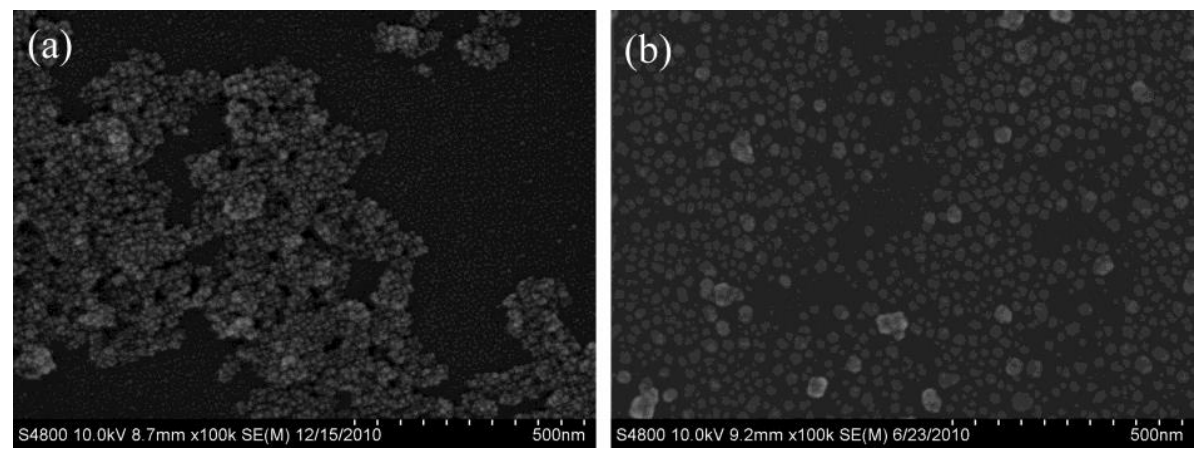

Figure 3. SEM images of as-prepared powders: (a) $\mathrm{ZrO}_{2}-\mathrm{C}$; (b) $\mathrm{ZrO}_{2}-\mathrm{S}$.

The characteristics of resistance versus relative humidity $(\mathrm{RH})$ of both samples with different surfactants were investigated (at room temperature in the relative humidity range from 15.7 to $95 \%$ ), as shown in Fig. 4. It can be seen that the decrease of impedance for $\mathrm{ZrO}_{2}-\mathrm{C}$ is greater than that for $\mathrm{ZrO}_{2}-\mathrm{S} . \mathrm{ZrO}_{2}-\mathrm{C}$ shows the high humidity sensitivity and the best linearity of the impedance. For $\mathrm{ZrO}_{2}-\mathrm{C}$, moreover, the impedance change is more than four orders of magnitude. Thus, the surfactants have a significant role on the humidity dependence of the impedance of sensors.

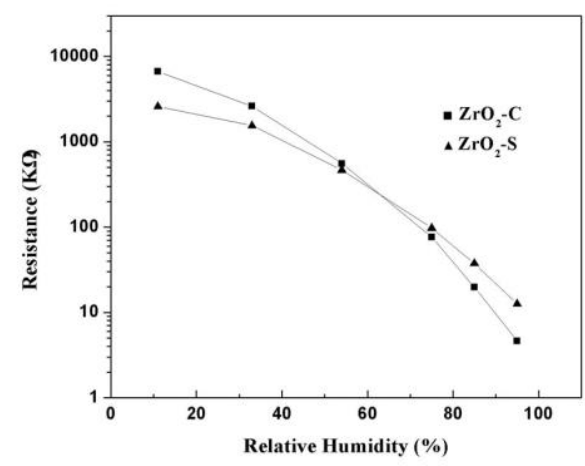

Figure 4. Resistance vs. $\mathrm{RH}$ plots of $\mathrm{ZrO}_{2}$ sensor with different surfactants.

The resistance variations of $\mathrm{ZrO}_{2}-\mathrm{C}$ with the increasing of relative humidity $(\mathrm{RH})$ measured under various frequencies was represented in Fig. 5. Obviously, the humidity dependences of the impedance of the sensor are influenced by the frequency and decreased at low frequency range (less than $100 \mathrm{~Hz}$ ). At low frequency region, with the relative humidity changed from $11 \%$ to $95 \%$, the impedance of the sensor varied four orders of magnitude. The highest sensing properties and largest decreasing of the impedance versus RH curve appeared at $100 \mathrm{~Hz}$. In the case of high frequencies $(100 \mathrm{KHz})$, however, the impedance of the sensor varied only four orders of magnitude. Therefore, the appropriate test frequency should be fixed at $100 \mathrm{~Hz}$.

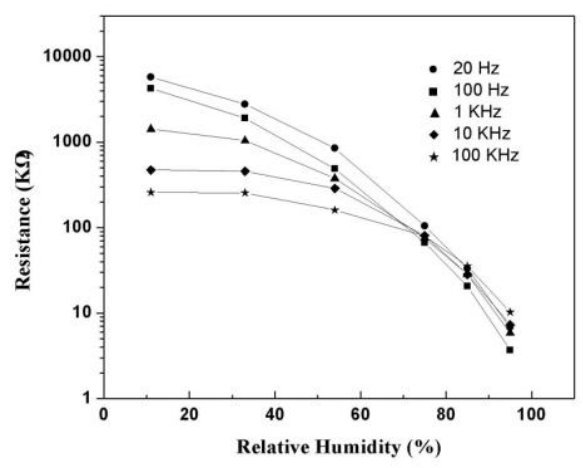

Fig. 5. Resistance vs. RH plots of $\mathrm{ZrO}_{2}-\mathrm{C}$ sensor at various frequencies. 
Response and recovery time were also investigated for estimating the performance of humidity sensor. The time taken by a sensor to achieve $90 \%$ to the total impedance change in the case of adsorption process and desorption process are defined as the response time and recovery time. The sensor is transferred from initial atmosphere $(15.7 \% \mathrm{RH})$ to target atmosphere $(95 \% \mathrm{RH})$ and transferred back to examine the response and recovery time, respectively. As shown in Fig. 6, the humidity sensor of $\mathrm{ZrO}_{2}-\mathrm{C}$ shows rapid response-recovery characteristics. The response time and the recovery time are about $60 \mathrm{~s}$ and $70 \mathrm{~s}$, respectively. In the cases of $\mathrm{ZrO}_{2}-\mathrm{S}$, however, the corresponding response and recovery time are $80 \mathrm{~s}$ and $110 \mathrm{~s}$, respectively. Such facts indicating that the cationic surfactant $(\mathrm{CTAB})$ has a significant effect on improving the performance of $\mathrm{ZrO}_{2}$ humidity sensors.

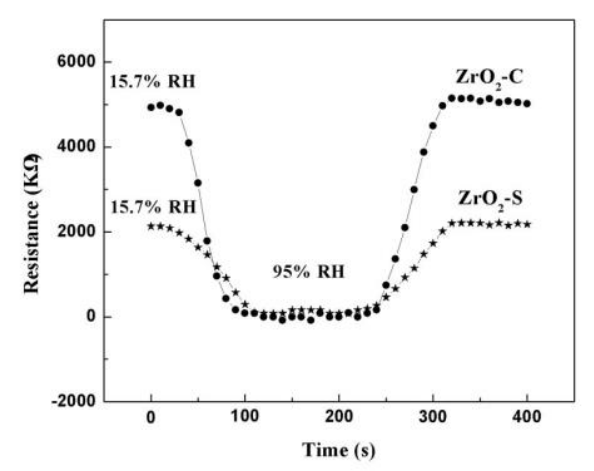

Fig. 6 Response and recovery characteristics of $\mathrm{ZrO}_{2}$ sensors with different surfactants.

As well known that the number of water molecules adsorbed on the powders has an important effect on electrical response. At low humidity, only a few water molecules are adsorbed (chemisorption mechanism), while several serial water layers will be formed at higher humidity by physisorption mechanism. In this paper, the large change in resistance also relate to the adsorption of water molecules on the surface of sensor film. In the case of low humidity, the sensor exhibits higher impedance which can be attributed to adsorption of a few water molecules on the surface of the film. However, the discontinuous layer of water molecules on the surface of the film leads to the difficulty of electrolytic conduction. For high humidity, however, more and more water layers can be formed on the surface of nanoparticles by physisorption mechanism [3, 9, 10]. As the dominant charged carriers, $\mathrm{H}^{+}$decomposed from water molecules can further decrease the impedance. In addition, on the other hand, in our study, the nano-sized grains and the high specific surface area also play an important role in the sensor performance. Both samples show nano-scaled particles which leads to much more grain boundaries which result in more active sites available for water molecules to react [5]. As mentioned above, $\mathrm{ZrO}_{2}-\mathrm{C}$ thin film shows higher specific surface area compared with $\mathrm{ZrO}_{2}-\mathrm{S}$. The water molecules are easily absorbed on the surface of the sensors due to the large surface of nanomaterials, which can improve the response and recovery characteristics.

\section{Summary}

Humidity sensing properties of nano-sized $\mathrm{ZrO}_{2}$ sensor with different surfactants were investigated. The cationic surfactant (CTAB) has a significant effect on improving the performance of $\mathrm{ZrO}_{2}$ humidity sensors. The impedance changed four orders of magnitude with $\mathrm{ZrO}_{2}-\mathrm{C}$. The response and recovery time of the sensor were $60 \mathrm{~s}$ and $80 \mathrm{~s}$, respectively. The studies of $\mathrm{CeO}_{2}$ with different content of surfactants are in progress, which will be published elsewhere.

\section{Acknowledgments}

This work was supported by the National Natural Science Foundation of China under Grant No. 11404032 and 11404034; and the Foundation of Education Department of Liaoning Province no. 
LY2016002.

\section{References}

[1] Z. M. Rittersma, Recent achievements in miniaturized humidity sensors-a review of transduction techniques, Sensor and Actuators A. 96 (2002) 196-210.

[2] E. Traversa, Ceramic sensors for humidity detection: the stateof-the-art and future developments, Sensor and Actuators B. 23(1995) 135-156.

[3] E. B. V’arhegyi, I. V. Perczel, J. Gerblinger, M. Fleisher, H. Meixner, J. Giber, Auger and SIMS study of segregation and corrosion behavior of some semiconducting oxide gas-sensor materials, Sensor and Actuators B. 18(1994) 569-572.

[4] S. Zampolli, I. Elmi, F. Ahmed, M. Passini, G.C. Cardinali, S. Nicoletti, L. Dori, Selectivity enhancement of metal oxide gas sensors using a micromachined gas chromatographic column, Sensor and Actuators B.105(2005) 400-406 .

[5] S. Ehrmann, J. Jungst, J. Goschnick, D. Everhard, Application of a gas sensor microarray to human breath analysis, Sensor and Actuators B. 65(2000) 247-249.

[6] Q. Kuang, C. Lao, Z. Wang, Z. Xie, L. Zheng, High-sensitivity humidity sensor based on a single $\mathrm{SnO}_{2}$ nanowire, Journal of the American Chemical Society. 129(2007) 6070-6071.

[7] G. Garcia-Belmonte, V. Kytin, T. Dittrich, J. Bisquert, Effect of humidity on the ac conductivity of nanoporous $\mathrm{TiO}_{2}$, Journal of Applied Physics. 94(2003) 5261-5264.

[8] E. B. V’arhegyi, I. V. Perczel, J. Gerblinger, M. Fleisher, H. Meixner, J. Giber, Auger and SIMS study of segregation and corrosion behavior of some semiconducting oxide gas-sensor materials, Sensor and Actuators B. 18(1994) 569-572.

[9] R. R. Piticescu, C. Monty, D. Taloi, A. Motoc, S. Axinte, Hydrothermal synthesis of zirconia nanomaterials, Journal of the European Ceramic Society. 21(2001) 2057-2060.

[10]X. Q. Fu, C. Wang, H. C. Yu, Fast humidity sensors based on $\mathrm{CeO}_{2}$ nanowires, Nanotechnology, 18(2007) 145503-145506. 